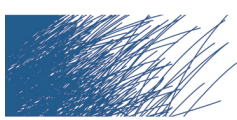

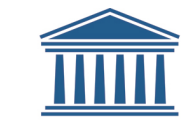 \\ UNIVERSITEIT \\ GENT
}

biblio.ugent.be

The UGent Institutional Repository is the electronic archiving and dissemination platform for all UGent research publications. Ghent University has implemented a mandate stipulating that all academic publications of UGent researchers should be deposited and archived in this repository. Except for items where current copyright restrictions apply, these papers are available in Open Access.

This item is the archived peer-reviewed author-version of:

Impact of whole-building hygrothermal modelling on the assessment of indoor climate in a library building

Steeman, M; De Paepe M and Janssens A

In: Building and Environment, 45, 1641-1652, 2010.

Optional: link to the article

To refer to or to cite this work, please use the citation to the published version:

Steeman M, De Paepe M and Janssens A (2010). Impact of whole-building hygrothermal modelling on the assessment of indoor climate in a library building. Building and environment 45 1641-1652. doi: 10.1016/j.buildenv.2010.01.012 


\title{
Impact of whole-building hygrothermal modelling on the assessment of indoor climate in a library building
}

\author{
M. Steeman ${ }^{1}$, M. De Paepe ${ }^{2}$ and A. Janssens ${ }^{1}$ \\ ${ }^{1}$ Ghent University, Department of Architecture and Urban Planning \\ Jozef Plateaustraat 22, B-9000 Gent, Belgium \\ ${ }^{2}$ Ghent University, Department of Flow, Heat and Combustion Mechanics, \\ Sint - Pietersnieuwstraat 41, B-9000 Gent, Belgium \\ Corresponding author: \\ Tel +3292643752 / Fax +3292644185 \\ Email: Marijke.Steeman@UGent.be
}

Keywords: moisture buffering, HAM , library, preservation, indoor climate

\begin{abstract}
.
This paper focuses on the importance of accurately modelling the hygrothermal interaction between the building and its hygroscopic content for the assessment of the indoor climate. Libraries contain a large amount of stored books which require a stable relative humidity to guarantee their preservation. On the other hand, visitors and staff must be comfortable with the indoor climate.

The indoor climate of a new library building is evaluated by means of measurements and simulations. Complaints of the staff are confirmed by measured data during the winter and summer of 2007-2008. For the evaluation of the indoor climate, a building simulation model is used in which the porous books are either described by a HAM model or by a simplified isothermal model. Calculations demonstrate that the HAM model predicts a more stable indoor climate regarding both temperature and relative humidity variations in comparison to the estimations by the simplified model. This is attributed to the ability of the HAM model to account for the effect of temperature variations on moisture storage. Moreover, by applying the HAM model, a good agreement with the measured indoor climate is found. As expected, a larger exposed book surface ameliorates the indoor climate because a more stable indoor relative humidity is obtained.

Finally, the building simulation model is used to improve the indoor climate with respect to the preservation of valuable books. Results demonstrate that more stringent interventions on the air handling unit are expected when a simplified approach is used to model the hygroscopic books.
\end{abstract}

\section{Introduction}

In libraries a comfortable indoor climate for both occupants and preservation and storage of valuable, i.e. hygroscopic, objects is necessary. Not much has been published yet on the evaluation of the indoor climate in libraries. Finn et.al. show a sensitivity analysis of a night ventilated library in a maritime climate [1]. The authors mainly focused on the evaluation of visitor's thermal comfort when varying internal gains, building mass, glazing, solar gains etc. To protect the book collection from possible condensation caused by the inlet ambient air, especially during night ventilation, a lower temperature limit of $13^{\circ} \mathrm{C}$ has been provided by a re heat system in the air handling unit.

However, the presence of hygroscopic materials, i.e. paper, plays an important role in the moisture balance of a library. Paper is able to absorb moisture when the relative humidity in the library increases and releases moisture when the room humidity decreases. Due to the presence of paper a more stable indoor climate is obtained. On the other hand, humidity variations can cause swelling and shrinking of the books, which in turn induces stresses and may result in mechanical damage e.g. cracks [2]. While humans feel comfortable over a wider relative humidity range, books require a stable indoor climate with limited daily variations. Additionally, the presence of people releasing heat and water vapour by respiration influence both the heat and mass balance of the library. Furthermore, the 
number of visitors and consequently the heat and moisture gains due to occupancy are not constant over time. Van Schijndel showed that additional moisture loads on rainy days due to wet clothes have to be taken into account when assessing the hygrothermal load of a building [3]. Per 10 people the moisture source load of wet clothing may be as high as $2.0 \mathrm{e}-4 \mathrm{~kg} / \mathrm{s}$ which is of the same order as respiration and perspiration by the people. While the presence of occupants and hence their comfort requirement is limited to the library's opening hours, it is important for books that the climate stays stable at all times. As a result, ideal set points should compromise between comfort for museum visitors and staff and the minimum temperature and relative humidity for the collection [4].

So far, a lot of experimental work has focused on the assessment of moisture buffering in, amongst others, paper and books, in order to get an idea of their hygrothermal behaviour. Various types of paper exist, such as newspapers, magazines, books, wallpapers etc. The latter may be coated with a paint of vinyl film which minimizes their moisture buffering ability. All types of paper have specific moisture transport properties which depend on the paper components and the manufacturing process [5], resulting in a different moisture buffering capacity. Also the way paper products are stored or exposed has an impact on their hygrothermal behaviour [6].

For instance, Svennberg et.al. conducted a room size experiment in which furniture and furnishings were gradually introduced in a climatic chamber [7]. A daily humidification and dehumidification cycle were introduced and the impact on the chamber relative humidity variations was evaluated. It was observed that when lightweight organic materials such as papers (which were positioned on a desk and in a waste basket) and textiles (consisting of curtains and a carpet) were exposed, lower relative humidity variations were measured.

In the scope of the international research project "Annex 41: Whole Building Heat, Air and Moisture Response (MOIST-ENG)", a similar experiment was conducted in a two-story test chamber in which the effect of buffering was studied by introducing finishing materials and furniture [8]. Moisture was produced for 10 hours in the climatic chamber, followed by 14 hours without moisture generation. Results showed that books in a book rack are able to take up and release moisture, but if simultaneously wooden panelling was introduced, the additional effect of the books was insignificant compared to the wood. This was partly explained by the larger exposed surface of the wooden panelling.

Svennberg and Rufelt carried out an inventory of hygroscopic materials in and evaluated the indoor climate of three identical offices in Sweden [9]. In in-situ measurements the microclimate was measured on different locations, e.g. behind books in an open and a closed book rack. They found that due to the large area of exposed paper and the relatively closed air space, the vapour content behind the books was lower than in the room centre. The difference was most pronounced for the closed bookshelf, where the vapour content was approximately two third of the vapour content in the room centre. Additionally, a time lag of 1-2 hours between variations in the centre and the rack was observed. The diurnal temperature variations behind books were smaller than in the centre, while the mean air temperature was quasi identical.

Derluyn measured the moisture buffer capacity of magazine and newspaper paper and showed that moisture buffering of books perpendicular to the fore-edge is higher than for the paper alone because moisture can penetrate deeply into the books due to the presence of the thin air layers between the paper sheets [10]. Measurements demonstrated that due to the presence of air layers between the paper sheets, a low paper fraction book is characterized by a higher effective permeability and a lower effective moisture capacity when compared to a high paper fraction book. Based on experiments, it was shown that books can significantly buffer peaks in moisture production as well as long term moisture productions when the available buffering surface is large enough.

Multizone building energy simulation (BES) programs can be used to numerically predict the indoor climate in a building from the design stage. All above examined studies prove the ability of paper and books to dampen relative humidity variations. This buffering effect may be significant, especially if the exposed hygroscopic surface is large enough, as in library buildings. Therefore, when predicting the 
temperature and relative humidity in a library building, a whole-building hygrothermal model is required which takes into account the complete interaction between the indoor air and the hygroscopic books.

This paper focuses on the importance of correctly modelling the hygrothermal interaction between the indoor air and the porous books, for the assessment of the indoor climate in a library building. First the studied library building and the air handling unit are described. The criteria used to evaluate the indoor climate with respect to thermal comfort and preservation of valuable books are elucidated. Next, the results of a measuring campaign in the library during the winter and summer of 2007-2008 are presented. In the second part of the paper the assumptions of a simplified isothermal model and a more detailed HAM model used to describe the hygroscopic content of the library building, are discussed. By means of a simulation model in TRNSYS [11], the influence of the amount of hygroscopic books and the level of detail used in the hygrothermal book model on the predicted indoor climate are investigated. To conclude, the simulation model is used to propose strategies for improving the indoor climate in the library.

\section{Description of the library building}

A new building for the Faculty of Economics and Business Administration at Ghent University was built in 2005-2006. The building consists of three floors. On the first floor a foyer and some offices are located. The second floor contains a large auditorium. On the top floor a library is situated having a glazed façade on the east and south side. At the east side a fixed shading is provided by means of large vertical columns while at the south side mobile exterior sunscreens are provided. The north and west side of the library are adjacent to a corridor and some offices separated by sound-proofing glass. The library has a floor area of $890 \mathrm{~m}^{2}$. The total exterior façade is about $350 \mathrm{~m}^{2}$, from which $95 \%$ is glazed. In the centre of the library an outdoor patio is located, glazed at all sides. A small office for the librarian is located at the south side of the library and is also fully glazed. A plan and section of the library building are presented in figure 1. Construction data are given in table 1.
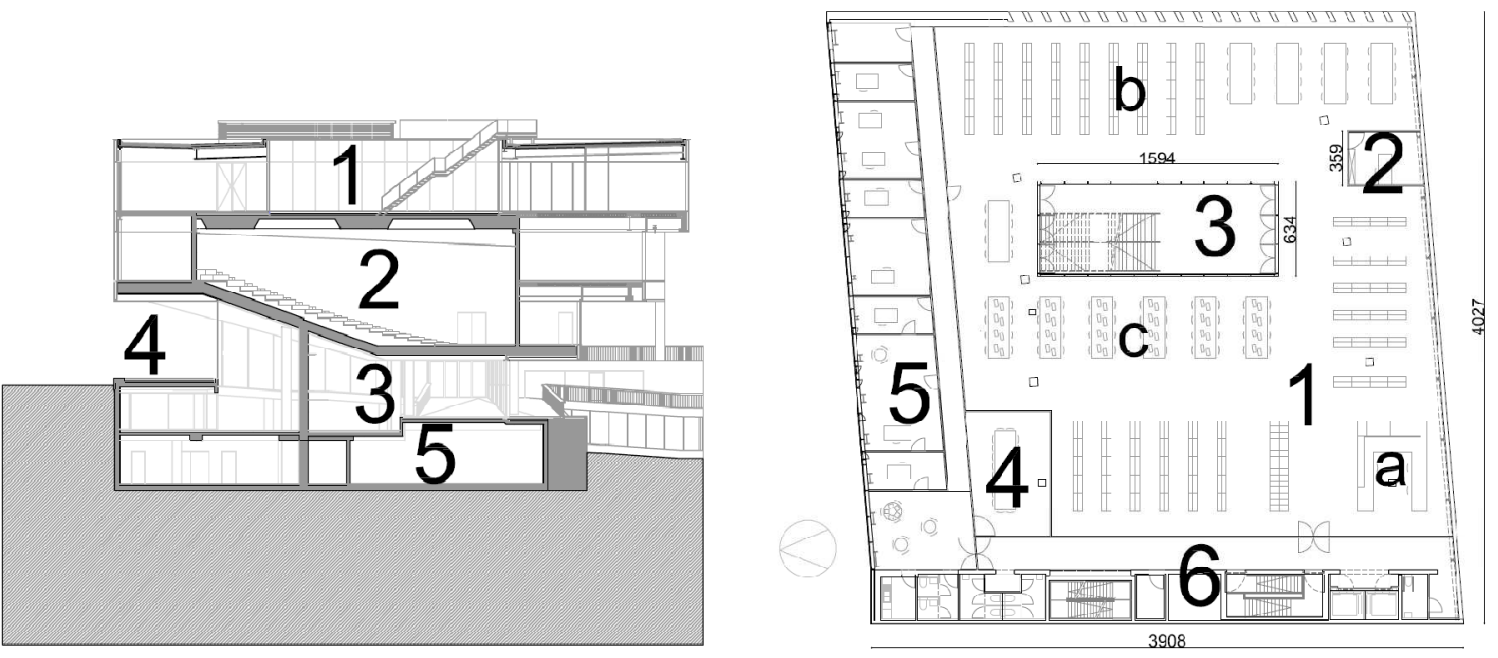

Figure 1. Left: section of the building with library and exterior patio (1), auditorium (2), foyer (3),entrance (4) and library archives and technical room (5). Right: plan of the third floor (right) with the library (1), the librarian office (2), the exterior patio (3), meeting room (4), corridor with offices (5) and building services section (6) - measuring locations (a), (b) and (c). 
Table 1. Building data of the library

\begin{tabular}{|c|c|c|c|c|c|}
\hline Dimensions & Area $\left(m^{2}\right)$ & Volume $\left(\mathrm{m}^{3}\right)$ & Height $(m)$ & & \\
\hline $\begin{array}{l}\text { Library } \\
\text { Office }\end{array}$ & $\begin{array}{l}890 \\
16.7 \\
\end{array}$ & $\begin{array}{l}2900 \\
55\end{array}$ & $\begin{array}{l}3.3 \\
3.3\end{array}$ & & \\
\hline Construction & Thickness (m) & $\lambda(\mathrm{W} / \mathrm{mK})$ & $\rho\left(\mathrm{kg} / \mathrm{m}^{3}\right)$ & $\mathrm{c}(\mathrm{J} / \mathrm{kgK})$ & $\mathrm{R}\left(\mathrm{m}^{2} \mathrm{~K} / \mathrm{W}\right)$ \\
\hline \multicolumn{6}{|c|}{ Roof $U=0.23 \mathrm{~W} / \mathrm{m}^{2} \mathrm{~K}$} \\
\hline Outside & - & - & - & - & 0.04 \\
\hline $\begin{array}{l}\text { EMPD- } \\
\text { membrane }\end{array}$ & 0.003 & 0.14 & 530 & 900 & 0.00 \\
\hline PIR Insulation & 0.1 & 0.03 & 30 & 1880 & 3.83 \\
\hline Light concrete & 0.03 & 0.17 & 750 & 850 & 0.17 \\
\hline $\begin{array}{l}\text { Hollow core } \\
\text { concrete slabs }\end{array}$ & 0.15 & 1.17 & 1500 & 840 & 0.13 \\
\hline \multicolumn{6}{|c|}{ Floor $U=0.36 \mathrm{~W} / \mathrm{m}^{2} \mathrm{~K}$} \\
\hline Inside & & - & - & - & 0.13 \\
\hline Linoleum & 0.01 & 0.17 & 1200 & 1400 & 0.06 \\
\hline Light concrete & 0.07 & 0.1 & 350 & 850 & 0.70 \\
\hline PÜR Insulation & 0.04 & 0.03 & 40 & 1470 & 1.44 \\
\hline Light concrete & 0.03 & 0.17 & 750 & 850 & 0.18 \\
\hline $\begin{array}{l}\text { Hollow core } \\
\text { concrete slabs }\end{array}$ & 0.2 & 1.17 & 1500 & 840 & 0.17 \\
\hline Inside & - & - & - & - & 0.13 \\
\hline \multicolumn{6}{|c|}{ Exterior (east-oriented) wall $U=0.33 \mathrm{~W} / \mathrm{m}^{2} \mathrm{~K}$} \\
\hline Outside & - & - & - & - & 0.04 \\
\hline $\begin{array}{l}\text { Reinforced } \\
\text { concrete }\end{array}$ & 0.55 & 2.2 & 2400 & 840 & 0.25 \\
\hline Air cavity & 0.2 & - & - & - & 0.05 \\
\hline Mineral wool & 0.12 & 0.05 & 100 & 840 & 2.40 \\
\hline Plasterboard & 0.025 & 0.16 & 950 & 840 & 0.16 \\
\hline Inside & - & - & - & - & 0.13 \\
\hline Window & $U=1.08 \mathrm{~W} / \mathrm{m}^{2} \mathrm{~K}$ & $g=0.5$ & & & \\
\hline \multicolumn{6}{|l|}{ Internal gains } \\
\hline Heat gains & Library & Office & & & \\
\hline People & 25 & 1 & & & 80W/pers. \\
\hline Lights & $893 m^{2}$ & $16.7 \mathrm{~m}^{2}$ & & & $10 \mathrm{~W} / \mathrm{m}^{2}$ \\
\hline Pc + screen & 25 & 0 & & & $100 \mathrm{~W} / \mathrm{Pc}$ \\
\hline Laptop & 0 & 1 & & & 70W/laptop \\
\hline Printer & 0 & 0 & & & $50 \mathrm{~W} /$ printer \\
\hline Total (W) & 13432 & 317 & & & \\
\hline Total $\left(\mathrm{W} / \mathrm{m}^{2}\right)$ & 4.56 & 5.76 & & & \\
\hline Moisture gains & Library & Office & & & \\
\hline People & 25 & 1 & & & $0.07 \mathrm{~kg} / \mathrm{h} /$ pers \\
\hline Total $(\mathrm{kg} / \mathrm{h})$ & 1.75 & 0.07 & & & \\
\hline Total $\left(\mathrm{g} / \mathrm{h} / \mathrm{m}^{2}\right)$ & 0.59 & 1.27 & & & \\
\hline
\end{tabular}

Two air handling units (AHU) including an indirect evaporative cooling system were installed to provide fresh air for the auditorium and the library. The AHU dedicated to the library, has a design air flow rate of $10.000 \mathrm{~m}^{3} / \mathrm{h}$ (approximately $3.3 \mathrm{~h}^{-1}$ ). The evaporative cooling system consists of a double cross flow heat exchanger in polypropylene $\left(1950 \times 1215 \times 997 \mathrm{~mm}^{3}\right)$. The AHU works in different operating modes, depending on the outside temperature and the air temperature in the library. In winter, basic heating is provided by a floor heating system having a minimum indoor air temperature set point of $2^{\circ} \mathrm{C}$ during occupancy. The system is e quipped with a night set back (set point $20^{\circ} \mathrm{C}$ ). The heat exchanger in the AHU is in that case used as a dry heat exchanger for heat recovery from the exhaust air. The return air can be partly recirculated by opening the mixing valve. An additional 
heating coil located downstream of the heat exchanger may further heat the supply air if necessary. In summer or mid-season, when the library requires cooling, different operating modes are possible: (1) indirect evaporative cooling, (2) free cooling and (3) night cooling. If the criteria for indirect evaporative cooling are fulfilled, the outdoor air is passed through the heat exchanger and indirectly cooled by the wetted secondary air. Nozzles located upstream of the heat exchanger are wetting the return air in the first part of the heat exchanger. The water is collected in the sump below the heat exchanger and recirculated. If indirect evaporative cooling is not possible, the heat exchanger is bypassed and free cooling with $100 \%$ outdoor air is provided. During warmer periods, cold outdoor air may be ventilated through the library at night in order to lower the indoor temperature by the following day. Both supply and return fans are frequency controlled and their air flow rates are balanced.

A schematic representation of the AHU is given in figure 2 [12]. Constitutive parts are indicated, as well as the supply and return air flows in case of indirect evaporative cooling or heat recuperation (no sprayed water) and in case the heat exchanger is bypassed (i.e. free cooling or night cooling). The AHU is continuously in operation from Monday - Saturday 07h-19h, on Sunday and holiday periods the AHU is not in operation. The following control strategy is implemented:

Day-time operation (from 07-19h):

a. $\theta_{i}<24^{\circ} \mathrm{C}: \dot{V}=\dot{V}_{\min }$ (hygienic ventilation)

i. $\theta_{e}<\theta_{i}$ : heat recuperation: $\theta_{s}=\theta_{h x}$

if $\theta_{h x}<17^{\circ} \mathrm{C}: \theta_{s}=17^{\circ} \mathrm{C}$ (heating coil)

ii. $\theta_{e}>\theta_{i}: \theta_{s}=\theta_{e}$

b. $\theta_{i}>24^{\circ} \mathrm{C}: \dot{V}=\dot{V}_{\max }$ (hysteresis $2^{\circ} \mathrm{C}$ )

i. $\theta_{e}>18^{\circ} \mathrm{C}$ and $\theta_{i, w b}>16^{\circ} \mathrm{C}$ : indirect evaporative cooling: $\theta_{s}=\theta_{h x}$

ii. $\theta_{e}<18^{\circ} \mathrm{C}$ or $\theta_{i, w b}<16^{\circ} \mathrm{C}$ : free cooling

1. $\theta_{e}<\theta_{i}$ : heat recuperation: $\theta_{s}=\theta_{h x}$ if $\theta_{h x}<17^{\circ} \mathrm{C}: \theta_{s}=17^{\circ} \mathrm{C}$ (heating coil)

2. $\theta_{e}>\theta_{i}: \theta_{s}=\theta_{e}$

Night-time operation (from 19-07h):

c. $\theta_{i}>25^{\circ} \mathrm{C}, \theta_{e}>10^{\circ} \mathrm{C}$ and $\theta_{i}-\theta_{e}>3^{\circ} \mathrm{C}: \dot{V}=\dot{V}_{\max }$

$\theta_{s}=\theta_{e}$ (night cooling until $\theta_{i}<22^{\circ} \mathrm{C}$ )

$\theta_{i}$ is the indoor air temperature, $\theta_{e}$ is the outdoor air temperature, $\theta_{i, w b}$ is the wet bulb temperature of the indoor air, $\theta_{h x}$ is the supply temperature behind the heat exchanger and $\theta_{s}$ is the temperature of the ventilation air supplied to the library $\left({ }^{\circ} \mathrm{C}\right)$. F or comfort reasons e.g. draft the minimum supply air temperature is limited to ${ }^{\circ} 7^{\circ} \mathrm{C}$. The air flow rate for hygienic ventilation $\left(\dot{V}_{\min }\right)$ is based on the minimal ventilation requirements for a medium indoor air quality (IDA2) [13]. Assuming a design occupancy of 50 persons it is $1100 \mathrm{~m}^{3} / \mathrm{h}\left(0.37 \mathrm{~h}^{-1}\right)$. The air flow rate is increased to the design air flow rate $\left(\dot{V}_{\max }=\right.$ $10.000 \mathrm{~m}^{3} / \mathrm{h}$ or $3.3 \mathrm{~h}^{-1}$ ) to enlarge the cooling capacity. The mobile sunscreen at the south façade are lowered if the total solar radiation on the façade is higher than $150 \mathrm{~W} / \mathrm{m}^{2}$, the wind speed is below $6 \mathrm{~m} / \mathrm{s}$ and the indoor temperature in the library exceeds $23^{\circ} \mathrm{C}$. The mobile sunscreens rise as soon as the indoor temperature drops below $22^{\circ} \mathrm{C}$. 


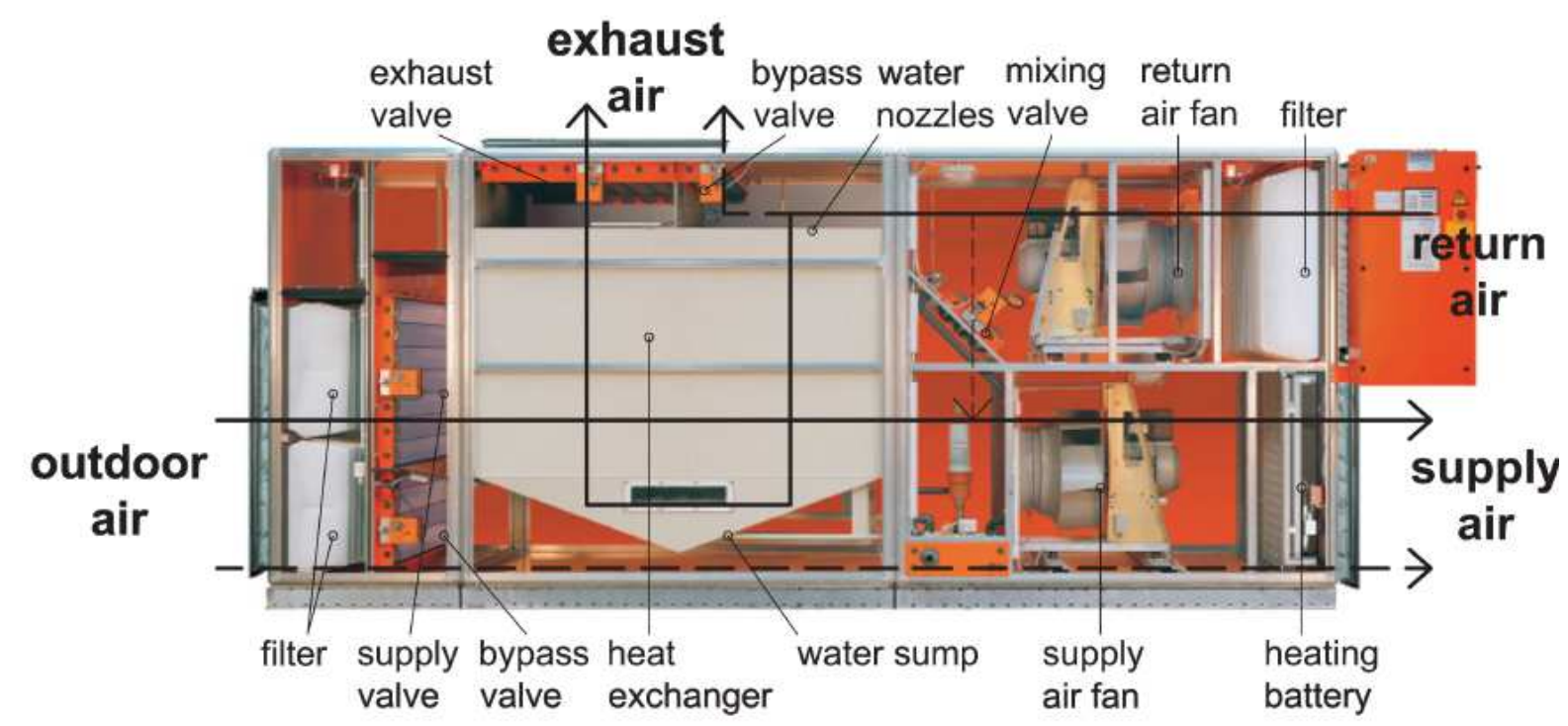

Figure 2. Scheme of the air handling unit. Two operation modes are indicated: air ventilated through bypass $\left(\_\right.$) and heat exchanger bypassed $\left(_{-}\right)$. By opening the mixing valve the return air is partly recirculated in winter (- - -) [12]

Note that measurements in the AHU showed that in the early morning the outdoor air is sometimes heated in the heat exchanger although this is not required, which may lead to a suboptimal performance of the system. The currently implemented control strategy takes into account the return air wet bulb temperature but does not look at the temperature difference between the dry bulb outdoor air and the wet bulb return air $\left(\theta_{e}-\theta_{i, w b}\right)$. Using the temperature difference between the dry bulb outdoor air and the wet bulb return air as a control parameter, may enhance the operation of the system. The reader is referred to [26] for more details on the measurements performed in the air handling unit.

\section{Measured indoor climate in the library}

To be able to evaluate the indoor climate an overview of common criteria for guaranteeing thermal and hygric occupant's comfort and for ensuring the preservation of books is discussed first.

\subsection{Comfort criteria}

The Adaptive Temperature Limits Indicator (ATG) takes into account the thermal adaptation of occupants to the indoor climate and is frequently used to evaluate thermal comfort in buildings [14]. The method relates the indoor operating temperature to the running mean outdoor temperature, which represents a weighted average of the temperature of the current day and the three preceding days. In the approach a differentiation is made between buildings in which the occupants can control the indoor climate e.g. by opening windows, and fully air-conditioned buildings. Thermal comfort is divided into three levels i.e. A, B and C. It is required that buildings meet the standard level B, corresponding to $80 \%$ thermal acceptability, to have a good indoor comfort. In contrast, less strict standards exist regarding occupant's hygric comfort. A too low relative humidity may dry the membranes in the eyes and nose too quickly, causing eye irritation and breathing discomfort. A too high relative humidity increases the friction between skin and fibres, which creates an uncomfortable feeling [2]. Additionally various studies showed that the perceived air quality is affected by the humidity of the air [15]: cooler drier air is perceived fresher and less contaminated. Furthermore, relative humidity indirectly influences thermal comfort due to latent heat losses by the respiratory tract and skin. A higher 
ambient relative humidity means that the skin can release less heat and thus the air is perceived as being warmer. For humans the climate is generally considered comfortable if the indoor relative humidity is between $30 \%$ and $70 \%$ [13].

In contrast, the impact of relative humidity on the preservation of hygroscopic objects is more significant. A stable relative humidity is essential to prevent the artefacts from changes in size or shape or to avoid the introduction of chemical reactions. Furthermore, a too high relative humidity may lead to condensation and mould growth while a too low relative humidity may induce cracks in porous materials. Precise indoor climate specifications concerning temperature and relative humidity exist for the preservation of valuable books and artwork: the relative humidity must be kept stable and diurnal and yearly/seasonal fluctuations must be minimized. Different tolerances are accepted depending on the type of collection and materials. Van Schijndel et.al. present a review of the climate recommendations for (wall)paper [16]. The consulted documents all gave similar criteria regarding the allowable relative humidity range. The requirements posed by ASHRAE [4] are based on similar criteria: the basis is an annual target relative humidity of $50 \%$ for a set point temperature between $1^{\circ} \mathrm{C}$ and $25^{\circ} \mathrm{C}$. Classes are defined ranging from $\mathrm{A} / \mathrm{A} \mathrm{A}$, corresponding to the highest possible control with a negligible or small risk of damage, to $D$, with a minimized control in which only the risk of mould growth is avoided. An overview of the ASHRAE preservation criteria is given in table 2. Note that while for the least strict preservation Classes $C$ and $D$ only requirements to the maximum and minimum admissible temperature and relative humidity are imposed, in the more severe Classes $A$ and $B$ also the temperature and relative humidity variations are limited. Besides ASHRAE, other institutions propose recommendations for the preservation of valuable objects. A good overview can be found in $[2,17,18]$. All documents follow the same trends and emphasize the importance of a stable indoor climate.

Table 2. ASHRAE conservation classes - adapted from [4]

\begin{tabular}{lllll}
\hline Class & Temperature & \multicolumn{2}{c}{ Relative humidity } \\
& Daily fluctuations & Value & Daily fluctuations & Value \\
\hline AA & $<2^{2} \mathrm{C}$ & $15-25^{\circ} \mathrm{C}$ & $<5 \%$ & $50 \%$ \\
A & $<2{ }^{\mathrm{C}}$ & $15-25^{\circ} \mathrm{C}$ & $<5 \%$ & $40-60 \%$ \\
$\mathrm{~B}$ & $<5 \mathrm{C}$ & $<30^{\circ} \mathrm{C}$ & $<10 \%$ & $40-60 \%$ \\
C & - & $<30^{\circ} \mathrm{C}$ & - & $25-75 \%$ \\
D & - & - & - & $<75 \%$ \\
\hline
\end{tabular}

In this paper, the ATG method will be used to evaluate thermal comfort in the library building. ATG Class B is assumed to give an acceptable comfort. The ASHRAE classification for the preservation of books in the indoor climate will be applied. Class $C$ is considered to be sufficient to guarantee preservation of the moderately valuable books which are currently stored in the library. Class $B$ or even Class $A$ will be required if the collection is extended to more valuable objects.

\subsection{Measurements}

Measurements in the library were carried out during two periods: from 05/07/2007 to 13/09/2007 (summer period) and from 14/11/2007 to 27/01/2008 (winter period). Temperature and relative humidity of the supply air were measured as well as temperature and relative humidity in the library on different locations (indicated on figure 1): on the entrance desk which is located on the south side of the library (a), at a book rack (at $\pm 1.5 \mathrm{~m}$ height) on the east side (b) and at the computers area ( \pm $0.7 \mathrm{~m}$ height) (c). Uncertainty on the measured temperature and relative humidity was respectively \pm $0.2^{\circ} \mathrm{C}$ and $\pm 3 \%$. No measurements were carried out in the librarians office. The measurement interval was five minutes. 
Complaints from the library employees were too dry air during winter and too high indoor temperatures, especially in the librarian's office, during summer. This was partly caused by failure of the sun shading at the south façade. As a result the doors to the interior patio were often opened on sunny days. These observations were partly confirmed by the measurements: figure 3a shows the measured temperature and relative humidity on different locations in the library and the temperature and relative humidity of the supply air during a winter period (17-22/12/2007). The indoor air temperature varies from $1^{\circ} \mathrm{C}$ to $24.5^{\circ} \mathrm{C}$. Measured te mperature at the south desk and the computer desk is similar, and is about $1-2^{\circ} \mathrm{C}$ higher than the temperature measured at the book rack. Figure $3 a$ furthermore shows that the heating coil was additionally heating the supply air almost every day. Due to the ventilation with dry outdoor air, the corresponding relative humidity in the library was very low. The relative humidity of the supply air drops to $10 \%$ and even lower (Figure $3 \mathrm{~b}$ ). The humidity ratio is very low and ranges from $2.2 \mathrm{~g} / \mathrm{kg}$ to $4 \mathrm{~g} / \mathrm{kg}$ (Figure 3c). The outdoor air temperature in this period varies from $-2.9^{\circ} \mathrm{C}$ to $6.1^{\circ} \mathrm{C}$. During the measured pe riod the relative humidity in the library ranged from $14 \%$ to $42 \%$, which clearly leads to complaints. The supplied air flow rate was not measured but was assumed to be around the hygienic ventilation rate.

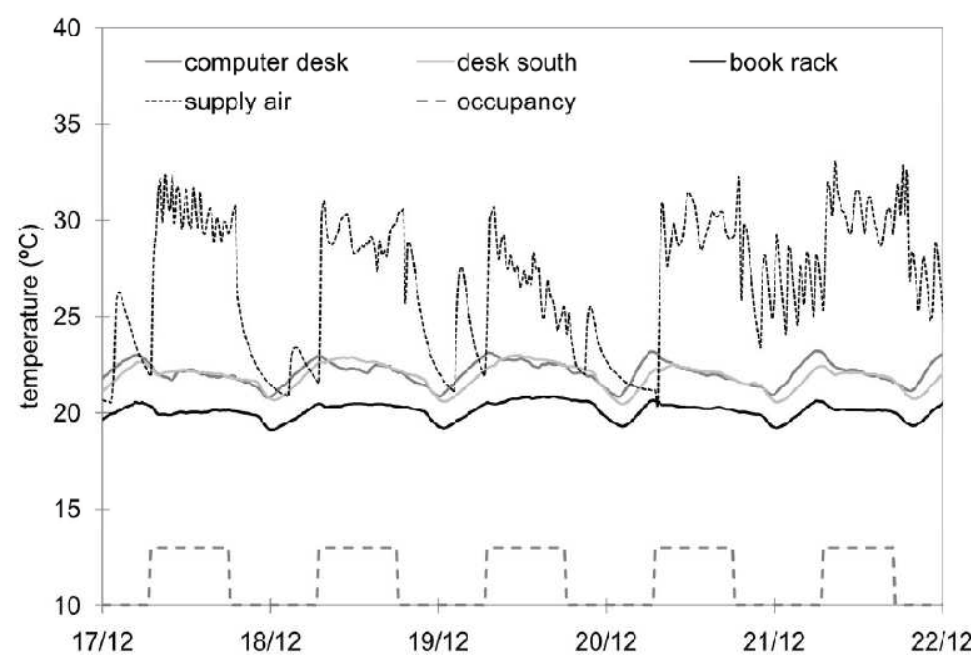

(a)

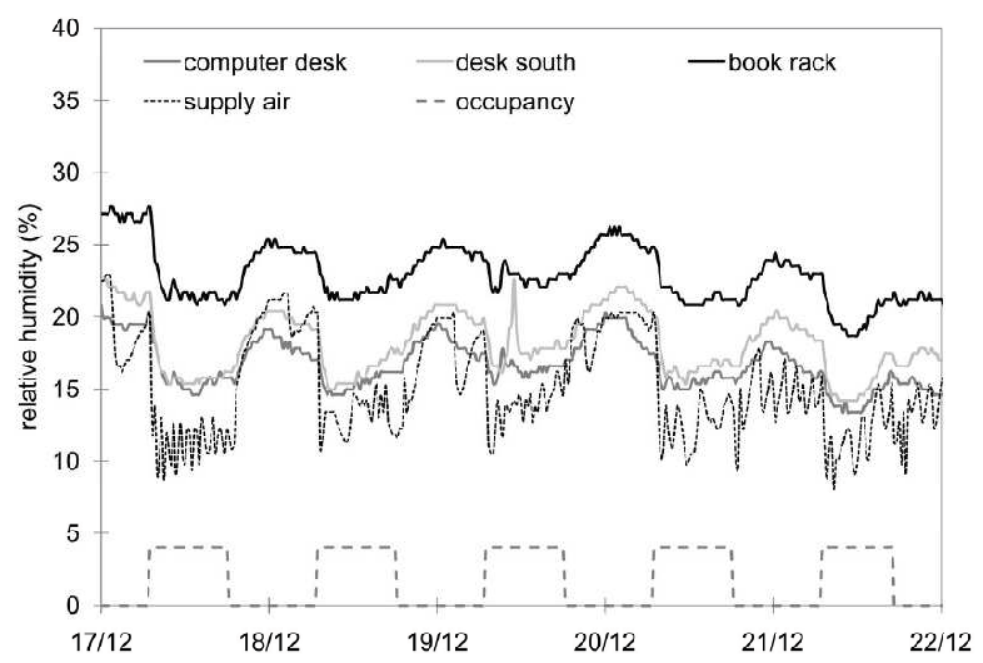




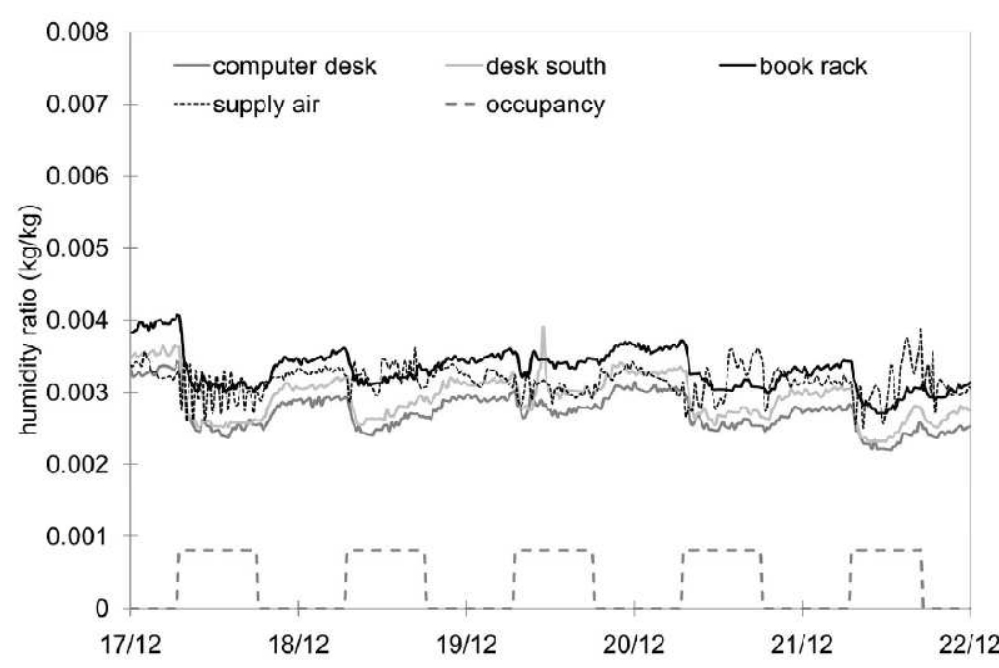

(c)

Figure 3. Temperature (a), relative humidity (b) and humidity ratio (c) in the library from 17-22/12/07.

Figure 4 shows an evaluation of the thermal indoor climate in the winter and the summer period. In winter, the measured outside temperature ranged from $-5.7^{\circ} \mathrm{C}$ to $14.5^{\circ} \mathrm{C}$. During the summer period the measured outside temperature ranged from $9.7^{\circ} \mathrm{C}$ to $34.3^{\circ} \mathrm{C}$. Note that the upper and especially the lower limits of the comfort classes are often exceeded during the occupancy hours. As a result the measured comfort is generally better in summer than in winter. On the east side of the library (i.e. near the bookrack) especially the lower temperature limits are exceeded, while on the south side (i.e. near the entrance desk) especially the upper limits are exceeded. The latter may be partly caused by the failure of the sunscreens. When looking at the measurements in the summer and winter period, the indoor thermal comfort in ATG Class B ranged from $70 \%$ to $93 \%$, which is acceptable (table 3 ). This does not seem to agree with the complaints of the staff. It must be noted that 2007 had a relatively cool summer, which was confirmed by measured temperature data of the Belgian Royal Meteorological Institute, KMI [19].

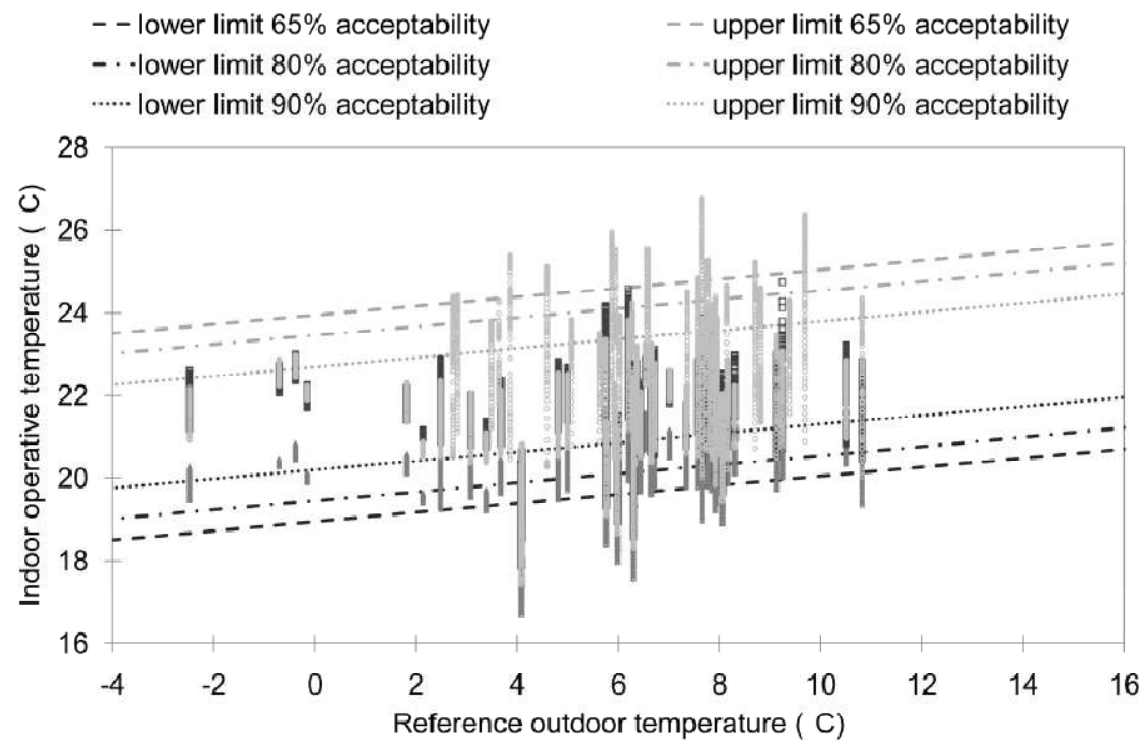




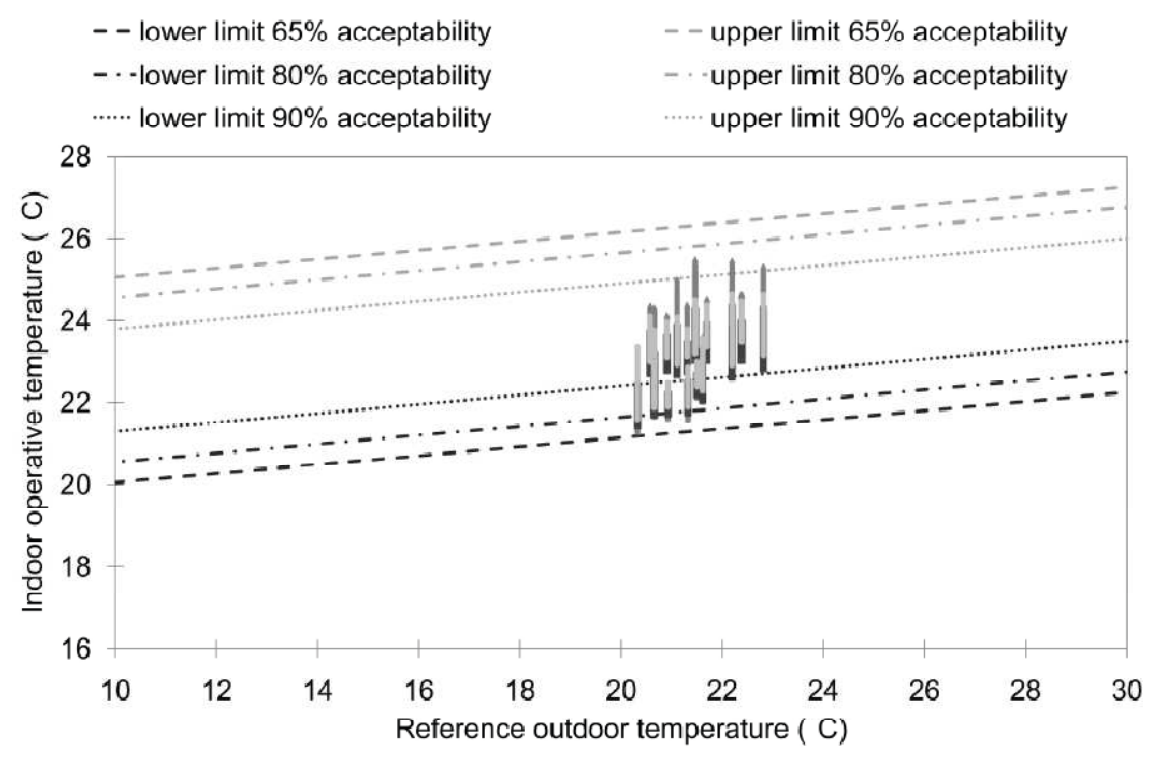

Figure 4. ATG Classes measured in library: winter period 14/11/2007 to 27/01/2008 (top) and summer period 05/07/2007 to 13/09/2007 (bottom). ( $\Delta$ ) book rack east, ( $\square$ ) computer desk and (०) desk south

Table 4 presents the evaluation of the indoor climate with respect to the preservation of books using the ASHRAE preservation classification given in table 2. In summer, preservation Class $C$ is always obtained and Class $B$ is reached during about $74 \%$ of the time. In contrast, Class $C$ is obtained during $73-86 \%$ of the time in winter. Due to the low indoor relative humidity in the library, Class $B$ is reached only during $4-16 \%$ of the time. Daily temperature variations are always smaller than $5^{\circ} \mathrm{C}$ and below ${ }^{\circ} \mathrm{C}$ during 40 to $100 \%$ of the time, depending on the location in the library. Daily relative humidity variations are below $10 \%$ during $52-92 \%$ and below $5 \%$ during 17 to $37 \%$ of the time. Measurements in winter showed a slightly more stable climate than summer measurements.

Table 3. Percentage of the occupancy hours the indoor climate is situated in the ATG classes (summer (S) from 05/07/2007 to 13/09/2007 and winter (W) from 14/11/2007 to 27/01/2007)

\begin{tabular}{lcccccc}
\hline \multirow{2}{*}{ ATG CLASSES } & \multicolumn{2}{c}{ Class A } & \multicolumn{2}{c}{ Class B } & \multicolumn{2}{c}{ Class C } \\
\hline Desk south & S & W & S & W & S & W \\
Book rack east & 67.5 & 72.9 & 93.4 & 90.3 & 95.6 & 95.3 \\
Computer desk & 59.2 & 78.4 & 87.2 & 67.7 & 94.4 & 86.3 \\
\hline
\end{tabular}

Table 4. Percentage of the total hours the indoor climate is situated in the ASHRAE preservation classes and daily temperature and relative humidity variations are limited (summer (S) from 05/07/2007 to $13 / 09 / 2007$ and winter (W) from 14/11/2007 to $27 / 01 / 2007$ )

\begin{tabular}{|c|c|c|c|c|c|c|c|c|}
\hline ASHRAE & \multicolumn{2}{|c|}{ Class A } & \multicolumn{2}{|c|}{ Class B } & \multicolumn{2}{|c|}{ Class C } & \multicolumn{2}{|c|}{ Class D } \\
\hline CLASSES & $\mathrm{S}$ & W & $\mathrm{S}$ & W & $\mathrm{S}$ & W & $\mathrm{S}$ & W \\
\hline Desk south & 49.4 & 5.8 & 72.6 & 8.4 & 100 & 78.2 & 100 & 100 \\
\hline Book rack east & 54.4 & 10.6 & 73.7 & 15.8 & 100 & 85.9 & 100 & 100 \\
\hline Computer desk & 57.2 & 3.1 & 74.1 & 4.3 & 99.8 & 72.6 & 100 & 100 \\
\hline DAILY & \multicolumn{2}{|c|}{$\mathrm{RH}<5 \%$} & \multicolumn{2}{|c|}{$T<2^{\circ} \mathrm{C}$} & \multicolumn{2}{|c|}{$\mathrm{RH}<10 \%$} & \multicolumn{2}{|c|}{$\mathrm{T}<5^{\circ} \mathrm{C}$} \\
\hline FLUCTUATIONS & $\mathrm{S}$ & W & $\mathrm{s}$ & W & $\mathrm{s}$ & W & $\mathrm{S}$ & W \\
\hline Desk south & 17.4 & 26.7 & 88.4 & 38.7 & 52.2 & 76.0 & 100 & 100 \\
\hline Book rack east & 24.5 & 37.3 & 72.5 & 74.7 & 63.8 & 92.0 & 100 & 100 \\
\hline Computer desk & 27.5 & 37.3 & 94.2 & 37.3 & 63.8 & 84.0 & 100 & 100 \\
\hline
\end{tabular}




\section{Building simulation model}

The library was modelled in the Building Energy Simulation (BES) program TRNSYS [11]. In multizone building models, a common assumption is that the indoor air is well-mixed. This means that temperature and vapour pressure are equal in every point of the room.

The building model consists of two zones: the library and the librarian's office. The floor, north and west walls of the library were assumed to be adiabatic because they are adjacent to other occupied spaces. Apart from the building, also the AHU and its control strategy are modelled in TRNSYS. The AHU's heating coil was considered to be an ideal system of which the set point is always reached. For reasons of convergence, hysteresis on the cooling set point $\left(2^{\circ} \mathrm{C}\right)$ was included. Based on the number of people counted on different moments in the library, an average occupation of 25 persons was assumed. Occupancy is daily (Monday to Saturday) from 08-18h, the internal heat and moisture gains were calculated accordingly (table1).

The modelling approach used to describe the hygroscopic content in the library and the indirect evaporative cooling system will be discussed in the next sections.

\subsection{Modelling hygroscopic books}

The non-steady state convective moisture balance for the indoor air in the library, in terms of the partial water vapour pressure, is presented in Equation 1.

$G_{p}+G_{s y s}+\frac{n V}{R_{v} T_{i}}\left(p_{e}-p_{i}\right)=\frac{V}{R_{v} T_{i}} \frac{d p_{i}}{d t}+\sum_{j} A_{j} \beta_{j}\left(p_{i}-p_{s, j}\right)$

In Equation $1 \mathrm{G}_{\mathrm{p}}$ is the moisture gain by e.g. people, activities etc. $(\mathrm{kg} / \mathrm{h}), \mathrm{G}_{\mathrm{sys}}$ are the moisture gains or removals due to HVAC-systems (e.g. humidification or dehumidification, in $\mathrm{kg} / \mathrm{h}$ ), $\mathrm{n}$ is the air change rate $(1 / \mathrm{h}), V$ is the room volume $\left(m^{3}\right), R_{v}$ is the gas constant for water vapour (i.e. $462 \mathrm{~J} / \mathrm{kgK}$ ) and $T_{i}$ is the indoor temperature $(K) . p_{e}$ and $p_{i}$ are respectively the exterior and interior partial vapour pressure $(\mathrm{Pa}), \mathrm{A}$ is the exposed hygroscopic surface $\left(\mathrm{m}^{2}\right), \beta$ is the convective mass transfer coefficient at the surface $\left(\mathrm{kg} / \mathrm{Pam}^{2} \mathrm{~s}\right)$ and $\mathrm{p}_{\mathrm{s}}$ is the surface vapour pressure $(\mathrm{Pa})$.

The available hygroscopic content in the library primarily consists of the books in the book racks with open shelves. Nowadays different approaches can be used to take the presence of hygroscopic books into account, the difference between the models is determined by the way the last term of Equation 1 is described.

\section{a. HAM model}

So-called HAM-models (Heat, Air and Moisture) solve the preservation equations for heat and mass transfer in porous materials and may be coupled to multizone building models or CFD-models in order to model the response of a room or the moisture distribution around valuable hygroscopic objects $[20,21]$. The scope of this paper is limited to multizone models. A recently developed transient 1D HAM model is used which takes into account vapour diffusion in porous materials. The model iteratively solves the coupled heat and mass transfer equations using a control volume method and an implicit discretization scheme and is integrated in TRNSYS [11]. More details about the model, its coupling and validation can be found in Steeman et.al. [20].

The books are considered to be a 1D system of parallel air layers and paper layers in which the moisture capacity of air can be neglected [5]. Water vapour transported via the air layer is not buffered by the air itself, but is almost immediately buffered by the paper sheets (Eq. 2). Due to the limited 
thickness of the paper the moisture is quickly redistributed and a 1D moisture front is attained in the paper. The water vapour permeability of the books can be determined both by the water vapour permeability of the paper and the air layers, weighted with their respective fraction values (Eq. 3).

$w_{b}=\psi_{p} \cdot w_{p}$

$\delta_{b}=\psi_{p} \cdot \delta_{p}+\left(1-\psi_{p}\right) \cdot \delta_{a}$

In Equations 2 and $3 w_{b}$ and $w_{p}$ are the moisture content of the book and the paper, $\psi_{p}$ is the paper fraction of the books, $\delta_{\mathrm{b}}$ and $\delta_{\mathrm{p}}$ are the vapour permeability of the book and the paper, and $\delta_{\mathrm{a}}$ is the vapour permeability of air (approximately $2.0 \mathrm{e}-10 \mathrm{~kg} / \mathrm{Pams}$ at $20^{\circ} \mathrm{C}$ ).

Derluyn [5] showed that a paper fraction of $75 \%$ yields good results for books standing on a book rack. Preliminary simulations with a lower paper fraction of e.g. $50 \%$ showed to have limited influence on the calculated relative humidity in the library. The density of paper is $840 \mathrm{~kg} / \mathrm{m}^{3}$, the specific heat capacity is $750 \mathrm{~kg} / \mathrm{m}^{3}$ and the thermal conductivity is $0.06 \mathrm{~W} / \mathrm{mK}$. The water vapour resistance factor and the sorption isotherm of books with 75\% paper fraction are given by Equations 4 and 5 . Measured material properties of magazine paper were used [5].

$\mu=\left(0.25+5.21 \cdot 10^{-7} \cdot \exp (11.07 \cdot \phi)\right)$

$w=189.08 \cdot\left(1-\frac{\ln (\phi)}{0.019}\right)^{\frac{-1}{1.8}}$

\section{b. Effective capacitance model}

In contrast to the above described whole-building hygrothermal model, the focus of most multizone BES tools is on the thermal response of the building while the relative humidity is calculated in a simplified way. An approach often applied in BES is to lump the hygroscopic content of the room (envelope, furniture...) into one single room air node. This implies that the capacitance of the room air is fictively increased and the non-steady state moisture balance of the room given in Equation 1 is reduced to Equation 6. The Effective Capacitance (EC) model available in TRNSYS is an example of such a lumped approach and is used in this work. In order to take into account the hygroscopic buffering in a more correct way, Roels and Janssen [22] proposed a method which relates the multiplication factor $\mathrm{M}$ for the room air moisture capacity to the measured moisture buffering value (Equation 7). $\mathrm{MBV}_{8 \mathrm{~h} / \mathrm{h}}$ is the measured moisture buffering value in $\mathrm{kg} / \mathrm{m}^{2} / \% \mathrm{RH}$ respectively for 1 and 8 hour cyclic step change (de)sorption measurements as defined in the Nordtest Moisture Buffer Value protocol [23].

Using the coupled TRNSYS-HAM model [20] the Nordtest protocol was applied to a book surface in order to estimate its MBV-value: a relative humidity of step of $75 \%$ during 8hours followed by a step change to $33 \%$ for 16 hours. The initial conditions were $33 \%$ and $20^{\circ} \mathrm{C}$. Values of $\mathrm{MBV}_{8 \mathrm{~h} / \mathrm{h} \text { h were }}$ derived from the change in moisture content after 8 hours and after 1 hour and were respectively 2.37 and 0.58 . These values agree well with measurement results (i.e. $M B V_{8 h}=2.45 \mathrm{~kg} / \mathrm{m}^{2} / \% R H$ and $\mathrm{MBV}_{1 \mathrm{~h}}=0.72 \mathrm{~kg} / \mathrm{m}^{2} / \% \mathrm{RH}$ ) carried out by Janssen en Roels on a similar book rack [22].

$G_{p}+G_{s y s}+\frac{n V}{R_{v} T_{i}}\left(p_{e}-p_{i}\right)=M \cdot \frac{V}{R_{v} T_{i}} \frac{d p_{i}}{d t}$

$M=1+\left[100 \cdot A \cdot\left(M B V_{8 h}+(1-\alpha) \cdot M B V_{1 h}\right) /\left(V \cdot \rho_{v, \text { sat }}\right)\right]$ 
In the above Equations 7 and $8 \mathrm{M}$ is a multiplication factor (-), $\alpha$ is a weighting factor depending on the length of the actual moisture production interval $(-)$ and $\rho_{v, \text { sat }}$ is the saturated interior vapour density $\left(\mathrm{kg} / \mathrm{m}^{3}\right)$.

An important drawback is that in the Effective Capacitance model the heat and moisture balance are decoupled. In other words, moisture buffering in porous materials is described in an isothermal way. In contrast, the coupled TRNSYS-HAM model simultaneously solves the preservation equations for heat and mass transfer in the room air and in multiple porous surfaces. Furthermore, the coupled HAM model enables to take into account the moisture-dependency of the thermal conductivity and the latent effect of absorption and desorption on the room air heat balance.

\section{c. Comparison models}

In a preliminary analysis, the accurateness of using a simplified EC model compared to a complete HAM model is assessed if a certain amount of hygroscopic books is available in the library: $800 \mathrm{~m}^{2}$, $1400 \mathrm{~m}^{2}$ and $2400 \mathrm{~m}^{2}$. The books are assumed to be on average $15 \mathrm{~cm}$ thick. The multiplication factor $\mathrm{M}$ in the lumped model is calculated using Eq. 7 and is $4.8,7.7$ and 12.2 respectively (at $20^{\circ} \mathrm{C}$ and $50 \%$ relative humidity). In this case, the weighting factor $\alpha$ in Eq. 7 is 1 , coinciding with a long moisture production interval (6-10 hours). In the HAM model the porous books are divided into 20 control volumes, ranging from $4.6 \mathrm{~mm}$ at the sides to $11.3 \mathrm{~mm}$ in the middle. The initial temperature and relative humidity are $20{ }^{\circ} \mathrm{C}$ and $50 \%$.

In order to compare the EC approach with the more complete HAM approach, the simulation model of the library is run for two situations: in both cases the outdoor temperature and relative humidity are $20{ }^{\circ} \mathrm{C}$ and $50 \%$ and no solar radiation is taken into a ccount. Furthermore water vapour $(3.5 \mathrm{~kg} / \mathrm{h})$ is produced from 09-17h and outdoor air is constantly supplied at $0.5 \mathrm{~h}^{-1}$. Results of the first situation are given in figure 5 (top): no heat gains are taken into account and the indoor temperature is kept constant at $20^{\circ} \mathrm{C}$. The agreement between both models is quite good in the isothermal simulation for different amounts of hygroscopic material.

However, the isothermal simulation represents a simplified case. In reality, the indoor air temperature in the library varies along the day due to interaction with occupants, external climate and the air handling unit. As a result, the isothermal assumption inherent to the EC model does not apply. Therefore, a second simulation case is investigated in which apart from moisture gains, heat gains are present in the library, for instance due to solar gains or internal gains by occupants or computers.

Figure 5 (bottom) demonstrates that in a non-isothermal simulation case the difference between both models becomes more pronounced. The discrepancy between both models is attributed to the fact that apart from water vapour pressure gradients, temperature gradients are able to induce moisture storage in hygroscopic materials. Inside a porous material, according to the temperature, a saturation water vapour pressure $\left(p_{\text {sat }}(\theta)\right)$ is established just above the water menisci in the capillaries. At a given relative humidity $(\phi)$ in the material, this results in a certain vapour pressure ( $p$ )above the water islands. When the temperature inside the porous material decreases, at the considered relative humidity, a lower vapour pressure is established above the capillaries: $p=\phi \cdot p_{s a t}(\theta)$. As a result, the books are no longer in equilibrium with the surrounding air and water vapour condenses in the pores (increase of capillary condensation), resulting in water vapour absorption from the indoor air to the hygroscopic books. On the other hand, a temperature increase leads to higher vapour pressures inside the porous structure. A vapour pressure gradient is established resulting in a release of moisture (desorption) from the hygroscopic material to the indoor air. Furthermore absorption is associated to latent heat release while desorption coincides with latent heat uptake. This phenomenon will further in this work be referred to as 'non-isothermal moisture buffering'. Notwithstanding this non-isothermal effect may be significant in the evaluation of the indoor climate 
with respect to preservation of (valuable) books in the library, it is neglected in the simplified isothermal modelling approaches such as the EC model.
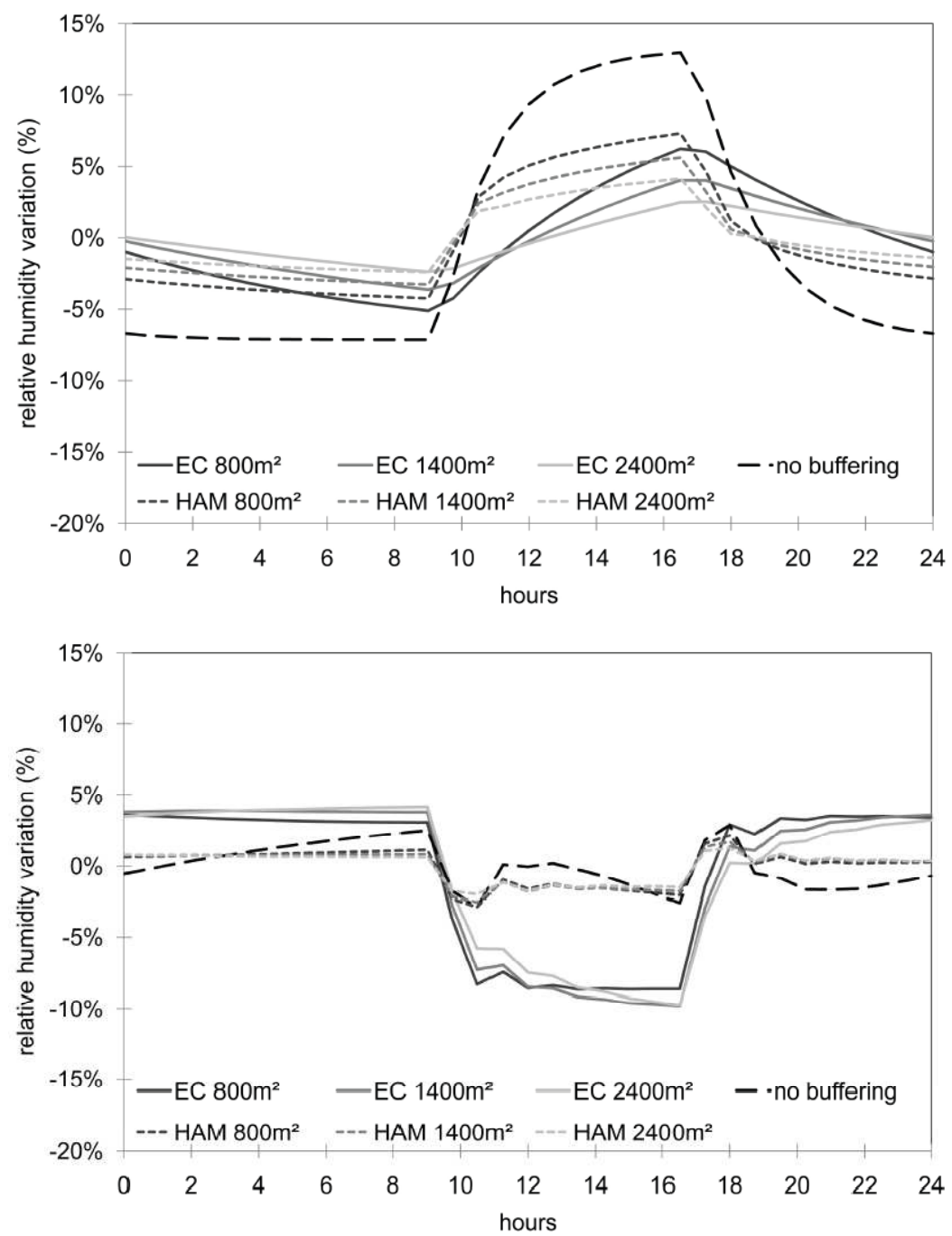

Figure 5. Relative humidity variation for stationary isothermal (top) and non-isothermal (bottom) simulation case

\subsection{Modelling indirect evaporative cooling}

To include an air handling unit containing indirect evaporative cooling into the building simulation model, a prediction of the supply air temperature behind the heat exchanger of the IEC system is required. A constant effectiveness approach is used to evaluate the performance of indirect evaporative cooling system without the need for a numerical model at component level (e.g. [24]). The IEC-effectiveness is defined by the ratio of the actual temperature reduction in the supply air realized by an IEC system $\left(T_{e}-T_{h x}\right)$, to the maximum possible temperature change, which is given by the temperature difference between the dry bulb of the outdoor air $\left(T_{e}\right)$ and the wet bulb of the return air entering the heat exchanger $\left(T_{i, w b}\right)$ (Eq. 8).

$I E C-$ effectiveness $=\frac{T_{e}-T_{h x}}{T_{e}-T_{i, w b}}$ 
Steeman et.al. showed that for a fixed ventilation rate through the heat exchanger the indirect evaporative cooling effectiveness is constant $[25,26]$. Using temperature measurements in the air handling unit before and behind the heat exchanger, the IEC-effectiveness could be derived. In Figure 6 , the difference between the dry bulb temperature of the supply air and the wet bulb temperature of the return air is plotted on the x-axis, the temperature drop in the supply air realized by IEC, is plotted on the $y$-axis, for measurements from 07/2008 to 08/2008. According to Eq.8, the IEC-effectiveness is given by the slope of the measured data in figure 6 . By linear regression an average IECeffectiveness $\left(\varepsilon_{\text {wet }}\right)$ of $85 \%$ is obtained with a good correlation coefficient $(0.99)$.

By consequence, the supply air temperature $\left(T_{h x}\right)$ behind the heat exchanger can be calculated in an analogous way to a dry heat exchanger using a wet effectiveness $\varepsilon_{\text {wet }}$ and keeping in mind that the lower limit for cooling the outdoor air $\left(T_{\text {lim }}\right)$ is physically determined by the wet bulb temperature of the indoor air $\left(T_{i, w b}\right)$ (Eq. 9). The effectiveness of the dry heat exchanger $\varepsilon_{d r y}$ was $70 \%$. These values correspond to the design air flow rate $\left(\dot{V}_{\max }=10.000 \mathrm{~m}^{3} / \mathrm{h}\right)$ and will be further used in the simulation model. In case of indirect evaporative cooling $T_{l i m}$ is equal to $T_{i, w b}$ and $\varepsilon$ is $\varepsilon_{w e t}$, during heat recovery $T_{\text {lim }}$ equals $T_{i}$ and $\varepsilon$ is $\varepsilon_{d r y}$.

$T_{h x}=T_{e}+\varepsilon \cdot\left(T_{e}-T_{\text {lim }}\right)$

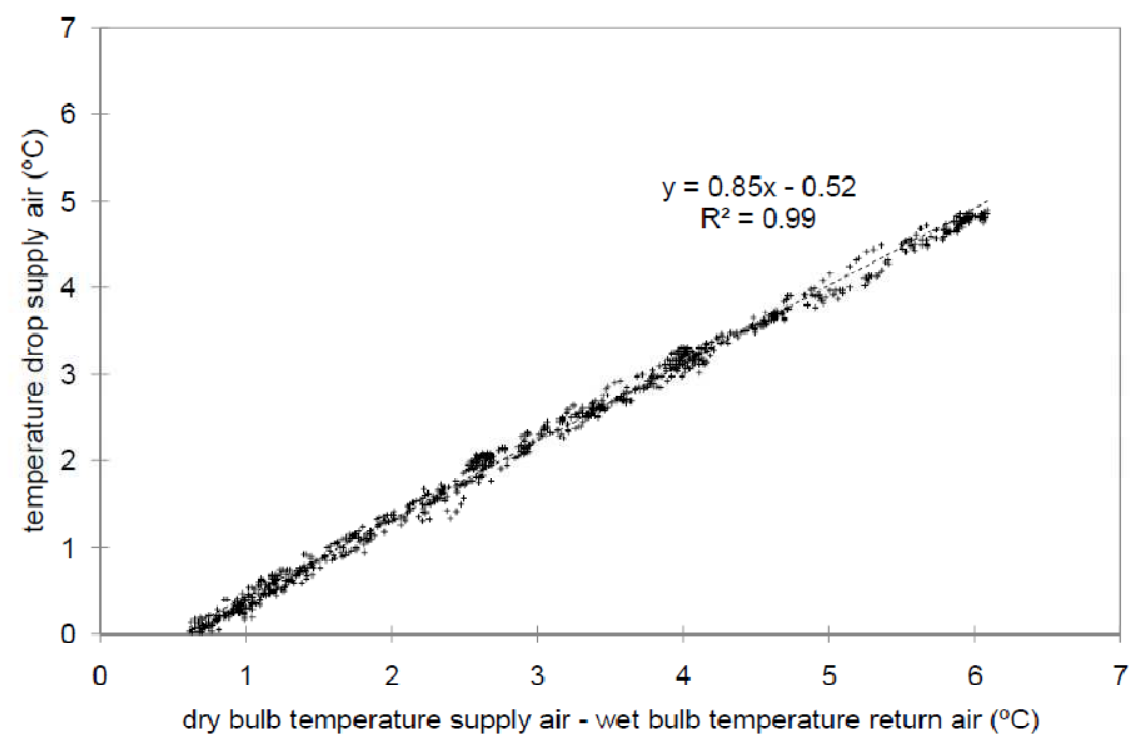

Figure 6. Relation between the temperature drop in the supply air and the difference between the dry bulb supply air temperature and the wet bulb return air temperature (07/2008 to 08/2008) [26].

Because the return air is wetted in the heat exchanger, an interaction exists between the relative humidity in the library, or its wet bulb temperature, and the performance of the indirect evaporative cooling system. By means of a sensitivity analysis on a small generic building Steeman et. al. concluded that for the studied case the influence of the moisture capacity was limited compared to the impact of the ventilation rate and the moisture production in the room [25].

\section{Simulation results}

In this section the influence of the available hygroscopic content and the hygrothermal modelling approach on the evaluation of the indoor climate in the library building is investigated. The parameters of the EC model and the HAM model are used as described in Section 4.1. 
In the simulations a weather file for Uccle, Belgium, was created using Meteonorm [27]. This program constructs the synthetic hourly weather data based on the climatological normals of 1961-1990 for a specific location. A preliminary evaluation showed that the outdoor temperature, relative humidity and solar irradiance used in the weather file agree fairly well with the outdoor climate during the measuring period [19]. All simulations were run for one year using a 15 minute time step.

\subsection{Influence of hygroscopic material and modelling approach}

Table 5 shows that in general ASHRAE preservation Class $C$ is predicted in the library. A larger amount of hygroscopic material ameliorates the stability of the climate regarding relative humidity and temperature variations, though the influence on the obtained preservation class is limited. On the other hand, the level of detail used in the book model is clearly more dominant to the predicted preservation class and the predicted daily temperature and relative humidity variations. For instance, the predicted percentage of time that the relative humidity variations are below $2 \%$ or $5 \%$ calculated with the coupled HAM model are twice the values calculated with the simplified model. By consequence, the applied hygrothermal model also affects the predicted preservation class. This is clearly noticeable when looking at the amount of time that the predicted indoor climate is situated in preservation Class B.

This can be explained by the effect of non-isothermal moisture buffering in the porous books. which was explained in Section 4.1: if the temperature in the library and hence at the book surface rises water vapour is instantly released from the books. In contrast if the temperature decreases water vapour is absorbed by the hygroscopic surfaces. As a result the relative humidity stays fairly stable. Furthermore water vapour release coincides with an uptake of latent heat while water vapour absorption is associated with heat release. By consequence, apart from the humidity variations, also the indoor temperature is more stable. Unlike in the coupled HAM model, simplified EC models do not couple the heat and moisture balance of the library and hence the influence of latent heat on the heat balance is neglected. The calculations with the coupled HAM model show that, due to the considerable amount of hygroscopic material, this may have an effect on the predicted temperature courses in the library.

When comparing table 4 and table 5 it is observed that the calculations with the coupled HAM model agree fairly well with the measured values. Daily temperature variations, especially below $2^{\circ} \mathrm{C}$, are slightly underpredicted. The percentage of time that the indoor climate is situated in preservation Class $A$ and $B$ is underestimated by the coupled HAM model, particularly compared to the measurements performed during summer. This is due to the fact that the predicted indoor relative humidity, as in the measurements, often drops below its acceptable limits for preservation, especially in winter.

Table 6 shows the influence of the amount of hygroscopic books on the predicted thermal comfort in the library and in the librarian's office. Note that while an evaluation of the indoor climate for preservation of the books covers the whole calculation period, thermal comfort (ATG) is assessed only during the occupancy hours in Table 6 . Due to the thermal capacity of the books, which is taken into account in the calculations, the predicted thermal comfort is affected by the amount of books. In the library thermal comfort is situated in ATG Class B during $84-98 \%$ of the occupancy hours and during about $79-82 \%$ of the time in the librarian's office. In the librarian's office, high temperatures are registered more regularly than in the library. A comparison of Table 3 and Table 6 proves that the predicted thermal comfort agrees quite well with the measured values. Generally a more favourable thermal climate is predicted when the HAM approach is used to model the hygroscopic books, although the influence is limited. This can be explained by the fact that a more stable indoor temperature is predicted with HAM, resulting in a smaller amount of temperature exceeding hours. 
Note that the use of a multizone model assumes well-mixed conditions. As a result temperature and vapour pressure in every point of the zone are equal and temperature and relative humidity distributions, as shown by the measurements on different locations in the library, cannot be captured. To counter this disadvantage, a coupled CFD-HAM model may be used instead $[21,28]$.

Table 5. Influence of the amount of books and the applied book model on the percentage of hours in the ASHRAE preservation classes and on temperature and relative humidity variations

\begin{tabular}{|c|c|c|c|c|c|c|c|c|}
\hline \multirow{2}{*}{$\begin{array}{l}\text { ASHRAE } \\
\text { CLASSES }\end{array}$} & \multicolumn{2}{|c|}{ Class A } & \multicolumn{2}{|c|}{ Class B } & \multicolumn{2}{|c|}{ Class C } & \multicolumn{2}{|c|}{ Class D } \\
\hline & HAM & EC & HAN & EC & HAM & EC & HAN & EC \\
\hline & 0.3 & 0.2 & 22.5 & 5.4 & 95.9 & 90.3 & 99.9 & 99.8 \\
\hline $1400 \mathrm{~m}^{2}$ & 0.5 & 0.3 & 28.0 & 6.6 & 99.1 & 90.6 & 100 & 99.7 \\
\hline $2400 m^{2}$ & 3.7 & 1.7 & 38.1 & 23.0 & 100 & 88.9 & 100 & 99.6 \\
\hline DAILY & \multicolumn{2}{|c|}{$\mathrm{RH}<5 \%$} & \multicolumn{2}{|c|}{$T<2^{\circ} \mathrm{C}$} & \multicolumn{2}{|c|}{$\mathrm{RH}<10 \%$} & \multicolumn{2}{|c|}{$T<5^{\circ} \mathrm{C}$} \\
\hline FLUCTUATIONS & HAM & EC & HAN & EC & HAM & EC & HAN & EC \\
\hline $800 m^{2}$ & 18.5 & 5.8 & 6.6 & 5.5 & 76.7 & 39.5 & 93.2 & 84.4 \\
\hline $1400 \mathrm{~m}^{2}$ & 30.1 & 7.9 & 7.4 & 5.8 & 84.1 & 44.9 & 97.0 & 88.5 \\
\hline $2400 m^{2}$ & 36.4 & 16.4 & 17.8 & 10.4 & 91.8 & 68.2 & 100 & 97.8 \\
\hline
\end{tabular}

Table 6. Influence of the amount books and the applied book model on the percentage of the occupancy hours the indoor climate is situated in the ATG classes

\begin{tabular}{llccccc}
\hline Library & \multicolumn{2}{c}{ Class A } & \multicolumn{2}{c}{ Class B } & \multicolumn{2}{c}{ Class C } \\
& HAM & EC & HAM & EC & HAM & EC \\
\hline $800 \mathrm{~m}^{2}$ & 72.6 & 65.6 & 89.5 & 84.3 & 95.2 & 90.9 \\
$1400 \mathrm{~m}^{2}$ & 77.3 & 67.5 & 92.3 & 86.1 & 96.8 & 92.4 \\
$2400 \mathrm{~m}^{2}$ & 89.2 & 81.9 & 98.5 & 94.6 & 99.5 & 98.0 \\
\hline Office & \multicolumn{2}{c}{ Class A } & \multicolumn{2}{c}{ Class B } & \multicolumn{2}{c}{ Class C } \\
& HAM & EC & HAM & EC & HAM & EC \\
\hline $800 \mathrm{~m}^{2}$ & 59.2 & 59.5 & 80.5 & 78.7 & 89.1 & 87.2 \\
$1400 \mathrm{~m}^{2}$ & 59.9 & 60.7 & 81.9 & 80.6 & 90.6 & 88.5 \\
$2400 \mathrm{~m}^{2}$ & 61.5 & 62.9 & 80.8 & 80.4 & 87.7 & 89.0 \\
\hline
\end{tabular}

\subsection{Indoor climate optimization}

The design of an HVAC system that provides a good indoor climate which, at the same time, guarantees the preservation of hygroscopic books and ensures the occupant's thermal comfort, is challenging. In the previous sections the demerits of the currently obtained indoor climate were highlighted and the influence of the amount of available hygroscopic material and the modelling approach on the indoor climate were evaluated.

Calculations with the currently implemented HVAC strategy show that the maximum relative humidity to ensure preservation of the books, is particularly exceeded during summer. The lower relative humidity limits are exceeded in winter when dry ventilation air is supplied to the library. Generally upper temperature limits are exceeded when the control parameters for indirect evaporative cooling or night cooling are not fulfilled. Additionally, daily variations in temperature and consequently in relative humidity are generally due to a change in the operating mode of the AHU, e.g. ventilation or cooling turned on or off. Still the actual indoor climate is sufficient for the currently stored books (ASHRAE preservation Class $\mathrm{C}$ ). However, if more valuable books have to be stored in the future, the indoor climate may need to be optimized.

Table 7 gives an overview of four proposed scenarios to improve the indoor climate in the library. The focus is on ensuring preservation of valuable hygroscopic books, since these requirements are most strict. First two scenarios intervene on limiting the daily temperature and relative humidity variations, while the third and fourth scenario intervene on controlling the relative humidity limits. In the reference simulation (i.e. scenario 0) the original AHU and control strategy was used, combined with $1400 \mathrm{~m}^{2}$ exposed books. All scenarios are evaluated in terms of thermal comfort, i.e. percentage of occupancy 
time the thermal climate in the library is situated in ATG Class B, and preservation, i.e. percentage of time the indoor climate is situated in ASHRAE preservation Class B. Furthermore the impact of the applied hygrothermal model, i.e. the coupled HAM model or the EC model, on the obtained indoor climate is investigated.

Table 7 summarizes the calculation results. In the reference simulation case, the HAM approach predicts a more stable and hence more favourable indoor climate for preservation and thermal comfort compared to the EC approach. First, the impact of eliminating night cooling from the AHU on the predicted indoor climate is evaluated. In this way the daily temperature and corresponding relative humidity variations may be minimized. However, the eliminating night cooling has a limited influence on the obtained preservation class: compared to the reference scenario, preservation Class $B$ is obtained during about $1-2 \%$ more often. On the other hand thermal comfort decreases during about $3 \%$ of the occupancy time, since temperature limits are exceeded more often. Secondly, the impact of a smaller air change rate for cooling is investigated. The AHU has a design air flow rate of $10.000 \mathrm{~m}^{3} / \mathrm{h}$ $\left(3.3 \mathrm{~h}^{-1}\right)$. By consequence ventilation with outdoor air has a large influence on the moisture balance of the library and hence on the relative humidity variations. Therefore the air change rate for cooling is varied from $2 \mathrm{~h}^{-1}$ at $24^{\circ} \mathrm{C}$ to $3.3 \mathrm{~h}^{-1}$ at $28^{\circ} \mathrm{C}$ in this scenario. In between $24^{\circ} \mathrm{C}$ and $28^{\circ} \mathrm{C}$ the implemented air change rate is linearly interpolated between $2 \mathrm{~h}^{-1}$ and $3.3 \mathrm{~h}^{-1}$. Compared to the reference calculation, preservation Class $B$ is ensured during an extra $2 \%$ of the time if the coupled HAM model is applied. However, thermal comfort in ATG Class B decreases for about $11-15 \%$ of the time. The first two scenarios demonstrate that meeting the criteria for guaranteeing preservation and ensuring occupant's thermal comfort is challenging: e.g. excluding night ventilation ameliorates the preservation of books but reduces the thermal comfort.

Table 7. Overview of the predicted indoor climate for different optimization scenarios

\begin{tabular}{llccc}
\hline Scenario & $\begin{array}{c}\text { Modelling } \\
\text { approach }\end{array}$ & $\begin{array}{c}\text { ASHRAE } \\
\text { Class B (\%) }\end{array}$ & $\begin{array}{c}\text { ATG } \\
\text { Class B (\%) }\end{array}$ \\
\hline 0 & Reference simulation & HAM & 28.0 & 92.3 \\
& & EC & 6.6 & 86.1 \\
1 & No night cooling & HAM & 30.0 & 89.1 \\
& & EC & 7.4 & 83.7 \\
2 & Variable air flow rate & HAM & 30.9 & 81.1 \\
& for cooling & EC & 5.9 & 71.3 \\
3 & Humidification & HAM & 84.4 & 92.4 \\
& (set point 40\%) & EC & 65.4 & 86.4 \\
4 & Humidification - dehumidification & HAM & 91.0 & 92.3 \\
& (set point 40\% - 60\%) & EC & 74.0 & 86.1 \\
\hline
\end{tabular}

When humidification and/or dehumidification is added to the AHU the predicted indoor climate improves to a large extent. When the indoor air is humidified to $40 \%$ relative humidity, preservation Class B is reached during about $84 \%$ of the time predicted with the HAM model, compared to $65 \%$ predicted by the EC approach. When both humidification (set point $40 \%$ relative humidity) and dehumidification (set point $60 \%$ relative humidity) are added, preservation is guaranteed respectively during $91 \%$ and $74 \%$ of the time. Humidification clearly improves the climate to a larger extent than dehumidification due to the low relative humidity measured in the library in winter. Humidification and dehumidification are modelled as ideal systems: set points are always reached and an effect on the heat balance of the library, e.g. by evaporation of water, is neglected.

The predicted total yearly load and the peak load for humidification and dehumidification are overestimated if the EC book model is used compared to the coupled HAM model (table 8). This can be explained by the more stable indoor climate predicted when using a more complete book model. When humidification is added to the AHU, the total humidification load predicted with the EC model is $50 \%$ higher than when calculated with the HAM approach. In scenario 4 the total humidification and dehumidification load in the library is overestimated by the EC model by $45 \%$ and $92 \%$ respectively, compared to the HAM approach. Humidification peak loads predicted using the EC model are $35 \%$ 
higher than using the HAM approach, while the dehumidification peak loads are overestimated by about $28 \%$.

Table 8. Predicted peak load and total yearly load for humidification and dehumidification for different optimization scenarios

\begin{tabular}{lccccc} 
& & \multicolumn{2}{c}{ Scenario 3 } & \multicolumn{2}{c}{ Scenario 4 } \\
& & Humidification & Dehumidification & Humidification & Dehumidification \\
\hline Peak load & HAM & 24.9 & - & 24.9 & 25.7 \\
(kg/h) & EC & 33.6 & - & 33.6 & 32.8 \\
Total yearly & HAM & 14080 & - & 14452 & 8176 \\
load (kg) & EC & 21228 & - & 21022 & 15675 \\
\hline
\end{tabular}

\section{Discussion}

Hygroscopic materials absorb and release water vapour when the ambient relative humidity increases or decreases. To predict the indoor relative humidity, nowadays different models are available to describe the convective water vapour balance of a room. In these models water vapour exchange between the room air and porous materials can be modelled in different ways. Models currently available in most BES programs, e.g. in TRNSYS, calculate moisture buffering generally in a simplified way and neglect the coupling between the heat and mass balance of the room air and the hygroscopic material. In contrast, more complete Heat, Air and Moisture (HAM) models solve the transient preservation equations for heat and mass simultaneously and hence predict water vapour absorption and desorption in a more accurate way.

In library buildings a large hygroscopic content is stored by the presence of books. These books generally have strict preservation criteria based on temperature and relative humidity limits and allowed diurnal and yearly fluctuations. Furthermore, the presence of occupants and hygroscopic books interact on the moisture balance of the library. By consequence the hygrothermal approach used to describe the hygroscopic books has an important effect on the predicted indoor climate regarding preservation.

Previous research showed that under isothermal conditions simplified and more detailed HAM models agree well [29]. However, when non-isothermal boundary conditions apply, due to their isothermal assumption simplified models are not able to predict the relative humidity correctly [24]. As the air temperature in the library varies due to solar gains, internal gains (occupants, computers etc.) and due to the interaction with the air handling unit (evaporative cooling, night cooling etc.), temperature variations should be taken into account when evaluating the indoor climate, since it has an important effect the hygrothermal behaviour of the porous books. Because the HAM model simultaneously solves the preservation equations for heat and mass, the effect of temperature variations on moisture buffering is taken into account and a more stable indoor climate regarding temperature and relative humidity variations is predicted. In contrast, this effect is not captured in simplified models which may lead to inaccurate results or a misjudgement of the indoor climate.

To summarize, the level of detail used when describing the hygrothermal interaction is highly important especially for buildings with high hygroscopic content such as libraries, museums... Neglecting non-isothermal moisture buffering may lead to a misjudging of the indoor climate in these buildings, and in turn, this may result in an improper sizing of the air handling unit.

\section{Conclusions}

The indoor climate in a new library building, disposing of an air handling unit containing indirect evaporative cooling, free cooling and night cooling, was evaluated by means of measurements and 
simulations in TRNSYS. Measurements showed that the relative humidity is, especially in winter, too low to guarantee preservation of the books and to ensure a comfortable climate for the occupants. Still the actual indoor climate proves to be sufficient for the currently stored books. However, if in the future more valuable books are exposed, the indoor climate requires improvement.

The presence of occupants and hygroscopic books interact on the moisture balance of the library. A simplified isothermal model (i.e. lumped model) and a more complete HAM model were applied to describe the hygroscopic content of the library. The latter accounts for the effect of temperature variations, e.g. due to visitors, solar radiation or interaction with the AHU, on moisture storage. As a result, the HAM model predicts a more stable climate regarding daily relative humidity variations, compared to the simplified EC model, which strongly ameliorates the preservation of books. A similar trend was observed in the measurements. Furthermore, calculations showed that a larger exposed hygroscopic surface enables to significantly damp temperature and humidity variations in the library, which consequently ameliorates the indoor comfort.

Finally, the simulation model is used to propose scenarios for an improvement of the indoor climate. Results showed that it is challenging to meet requirements for preservation and for thermal comfort at the same time. For instance excluding night ventilation or lowering the air change rate for cooling ameliorates the preservation of books but deteriorates thermal comfort. Adding a humidification system to the AHU enhances the preservation ability to a large extent. Furthermore, the yearly total and peak load for humidification and dehumidification are greatly overestimated if the simplified book model is used.

\section{Acknowledgements}

The results presented in this paper have been obtained within the frame of the research project IWTSB/51283/Steeman funded by the Flemish Institute for the Promotion and Innovation by Science and Technology in Flanders. Their financial support is gratefully acknowledged.

\section{Nomenclature}

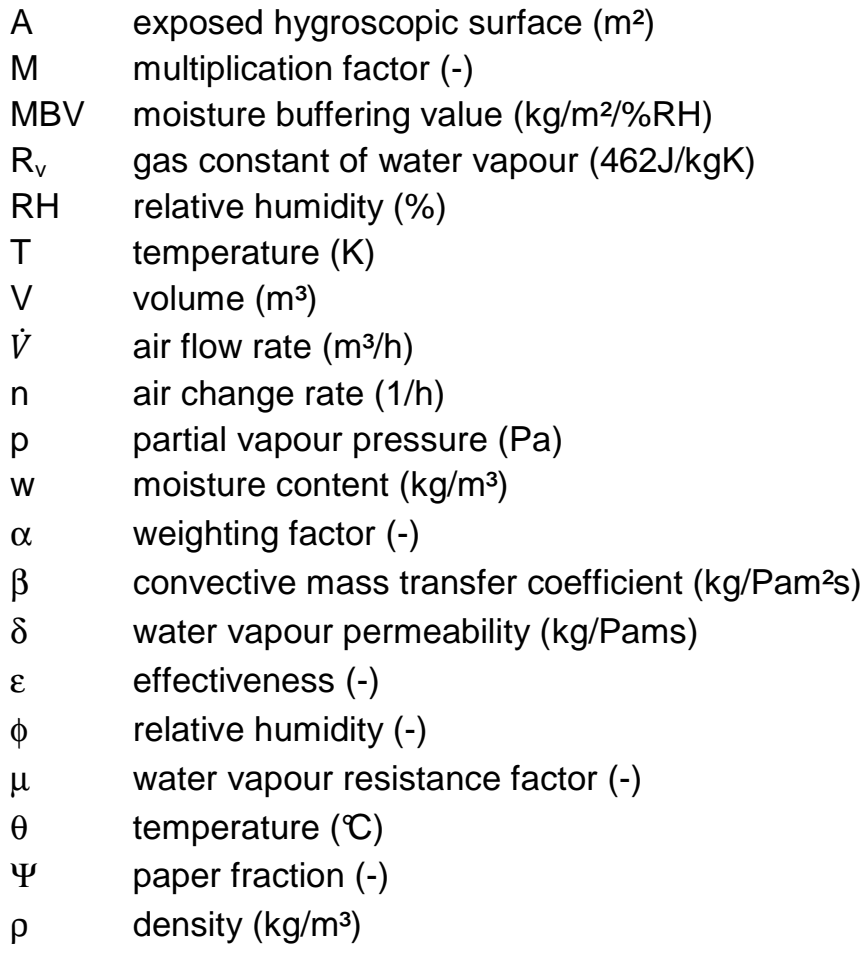




\begin{tabular}{ll}
\multicolumn{2}{l}{ Subscripts } \\
a & air \\
b & book \\
e & exterior \\
hx & heat exchanger \\
$\mathrm{i}$ & interior \\
$\mathrm{lim}$ & limit \\
$\mathrm{p}$ & paper \\
$\mathrm{s}$ & supply, surface \\
$\mathrm{sat}$ & saturation \\
$\mathrm{v}$ & vapour \\
$\mathrm{wb}$ & wet bulb
\end{tabular}

\section{References}

[1] Finn DP, Connolly D, Kenny P. Sensitivity analysis of a maritime located night ventilated library building. Solar Energy 2007; 81: 697-710.

[2] Harriman L, Brundrett G, Kittler R. Humidity control design guide for commercial and institutional buildings. American Society of Heating, Refrigerating and Air Conditioning Engineers, Artlanta, USA. 2001.

[3] Van Schijndel AWM. Estimating Values for the Moisture Source Load and Buffering Capacities from Indoor Climate Measurements. Journal of Building Physics. 2008; 31(3): 319-331.

[4] ASHRAE. Chapter 21 Museums, libraries and archives. In: ASHRAE, Applications Handbook (SI). American Society of Heating, Refrigerating and Air Conditioning Engineers. Atlanta. USA. 2007.

[5] Derluyn $\mathrm{H}$. Role of textiles and paper for stabilizing the indoor environment. Master Thesis KU Leuven. Belgium. 2006.

[6] Svennberg K. Moisture buffering in the indoor environment. Report TVBH-1016. Doctoral thesis. Building Physics LTH, Lund University, Sweden. 2006.

[7] Svennberg K, Hedegaard L and Rode C. Moisture Buffer Performance of a Fully Furnished Room. ASHRAE Special Publications, Proceedings of Buildings IX-Conference. 2004.

[8] Woloszyn M, Rode C. IEA Annex 41: Whole Building Heat, Air, Moisture Response. Subtask 1: Modelling Principles and Common Exercises. Final report. 2008.

[9] Svennberg K and Rufelt M. Moisture buffer performance in office premises: Inventory of surface materials and microclimate in three offices at Lund University (Manuscript n\%493).

[10] Derluyn H, Janssens H, Diepens J, Derome D, Carmeliet J. Can books and textiles help in controlling the indoor relative humidity? Building ASHRAE Conference. 2007.

[11] SEL, TRANSSOLAR, CSTB, TESS. Trnsys 16: A Transient System Simulation Programme. University of Wisconsin, Madison, USA. 2004.

[12] Menerga Klimatechnologie. www.menerga.de

[13] CEN EN 13779. Ventilation for non-residential buildings - performance requirements for ventilation and room-conditioning systems. Brussels, Belgium, 2004.

[14] van der Linden K, Boerstra AC et. al. Thermal indoor climate building performance characterized by human comfort response. Energy and Buildings 2002; 34: 737-744.

[15] Simonson CJ, Salonvaara M, Ojanen T. The effects of structures on indoor humidity - possibility to improve comfort and perceived air quality. Indoor Air 2002; 12: 243-251.

[16] Van Schijndel AWM, Schellen HL, Wijffelaars JL, van Zundert K. Application of an integrated indoor climate, HVAC and showcase model for the indoor climate performance of a museum. Energy and buildings 2008; 40: 647-653.

[17] Pavlogeorgatos G. Environmental parameters in museums. Building and Environment 2003; 38: 1457-1462.

[18] Holm A. IEA Annex 41 Whole Building Heat, Air, Moisture Response. Subtask 4: Applications: Indoor environment, Energy, Durability. Final report. 2008. 
[19] KMI. Royal Meteorological Institute. Belgium. www.kmi.be

[20] Steeman M, Janssens A, Steeman HJ, Van Belleghem M and De Paepe M. On coupling 1D nonisothermal heat and mass transfer in porous materials with a multizone building energy simulation model. Accepted for publication in Building and Environment. doi:10.1016/j.buildenv.2009.09.006.

[21] Steeman HJ, Van Belleghem M, Janssens A, De Paepe M. Coupled simulation of heat and moisture transport in air and porous materials for the assessment of moisture related damage. Building and Environment 2009; 44(10): 2176-2184.

[22] Janssen $\mathrm{H}$ and Roels S. Qualitative and quantitative assessment of interior moisture buffering by enclosures. Energy and Buildings 2009; 41(4): 382-394.

[23] Rode C, Peuhkuri R, Time B, Svennberg K, Ojanen T. Moisture buffer value of building materials. Journal of ASTM International 2007; 4(5).

[24] Steeman, M, Janssens, A. and De Paepe, M. A 1D stationary model for assessing the performance of indirect evaporative cooling. In: Proceedigns of the $8^{\text {th }}$ Symposium on Building Physics in the Nordic Countries. Volume 2, p 699-706. Copenhagen, Denmark. 2008.

[25] Steeman M, Janssens A and De Paepe M. Performance evaluation of indirect evaporative cooling using whole building hygrothermal simulations. Applied Thermal Engineering 2009; 29: 2870-2875.

[26] Steeman, M. Hygrothermal Modelling for Building Energy Simulation Applications. PhD thesis. Ghent University. Belgium. 2009.

[27] Meteotest. Meteonorm: global meteorological database for engineers, planners and education, Version 5.0. Bern, Switzerland, 2003.

[28] Steeman HJ, Janssens A, Carmeliet $\mathrm{J}$ and De Paepe M. Modelling indoor air and hygrothermal wall interaction in building simulation: Comparison between CFD and a well-mixed zonal model. Building and Environment 2009; 44(3): 572-583.

[29] Janssens A, De Paepe M. Effect of moisture inertia models on the predicted indoor humidity in a room. Proceedings of the $26^{\text {th }}$ AIVC Conference, Brussels, Belgium. 2005. 